\title{
Special considerations for obstructive sleep apnea in women
}

\author{
Ahmed Salem BaHammam
}

Received: 24 June 2009 / Accepted: 25 June 2009 /Published online: 19 September 2009

(C) Springer-Verlag 2009

Keywords Obstructive sleep apnea $\cdot$ Menopause $\cdot$ Rapid eye movement sleep

To the editor,

I read with interest the article by Dursunoglu et al. exploring the differences in the clinical presentation between men and women with obstructive sleep apnea (OSA) admitted to the sleep clinic [1]. The authors compared a number of variables including age between both groups (men and women) without exploring the menopausal status of women. With regards to women, including age without considering the menopausal status can be misleading. In females, the menopausal status is one of the most important risk factors and predictors of OSA regardless of age and body mass index (BMI), and its assessment is an essential part of any study looking into OSA in women. Young et al. assessed the association between the menopausal status and sleepdisordered breathing in women [2]. After adjusting for potential confounders like age, BMI, and smoking, the authors calculated the odds ratio $(95 \% \mathrm{CI})$ for an apnea hypopnea index (AHI) of more than five per hour of sleep to be $1.2(0.7-2.02)$ in perimenopausal and $2.6(1.4-4.8)$ in the postmenopausal women [2]. Some studies have suggested that sleep differences between men and women become less obvious in postmenopausal compared to premenopausal women [3, 4]. After menopause, the prevalence and severity of OSA in women approach that in men $[2,3,5]$. On the

The author has no personal or financial support or author involvement with organization(s) with financial interest in the subject matter or any conflict of interest to report.

A. S. BaHammam $(\bowtie)$

Sleep Disorders Center, King Saud University,

P.O. Box 225503, Riyadh 11324, Saudi Arabia

e-mail: ashammam2@gmail.com contrary, the AHI in premenopausal women is usually less than that in men [3]. Furthermore, women are more likely to exhibit apneas during rapid eye movement (REM) sleep [6, 7]. Dursunoglu et al. did not report the distribution of apnea in REM and nonREM sleep [1]. Women tend to have higher REM-related apnea than men. This was studied by O' Conner who found that most of the respiratory events in women occurred during REM sleep and $62 \%$ of women were categorized as REM-related apnea group compared to $24 \%$ of men [8]. This difference was not age or weight dependent [8]. Hence, it appears that women can be symptomatic at a lower AHI, possibly due to clustering of apneas and hypopneas mainly in REM sleep [4, 9].

\section{References}

1. Dursunoglu N, Ozkurt S, Sarikaya S (2009) Is the clinical presentation different between men and women admitting to the sleep laboratory? Sleep Breath 13:295-298

2. Young T, Finn L, Austin D, Peterson A (2003) Menopausal status and sleep-disordered breathing in the Wisconsin Sleep Cohort Study. Am J Respir Crit Care Med 167(9):1181-1185

3. Alotair H, Bahammam A (2008) Gender differences in Saudi patients with obstructive sleep apnea. Sleep Breath 12(4):323-9

4. Ware JC, McBrayer RH, Scott JA (2000) Influence of sex and age on duration and frequency of sleep apnea events. Sleep 23(2):165-170

5. Tishler PV, Larkin EK, Schluchter MD, Redline S (2003) Incidence of sleep-disordered breathing in an urban adult population: the relative importance of risk factors in the development of sleepdisordered breathing. Jama 289(17):2230-2237

6. Krishnan V, Collop NA (2006) Gender differences in sleep disorders. Curr Opin Pulm Med 12(6):383-389

7. Zhou XS, Shahabuddin S, Zahn BR, Babcock MA, Badr MS (2000) Effect of gender on the development of hypocapnic apnea/ hypopnea during NREM sleep. J Appl Physiol 89(1):192-199

8. O'Connor C, Thornley KS, Hanly PJ (2000) Gender differences in the polysomnographic features of obstructive sleep apnea. Am J Respir Crit Care Med 161(5):1465-1472

9. Young T, Evans L, Finn L, Palta M (1997) Estimation of the clinically diagnosed proportion of sleep apnea syndrome in middleaged men and women. Sleep 20(9):705-706 